\title{
Digital Filters' Quality Improvement Technique with Given Frequency Response Requirements
}

\author{
V.B. Kreyndelin ${ }^{1}$ \\ E.D. Grigorieva ${ }^{2}$ \\ Department of Theory of Electrical Circuits \\ Moscow Technical University of Communication and Informatics \\ ${ }^{1}$ vitkrend@gmail.com, ${ }^{2}$ ed.grigorieva@yandex.ru
}

\begin{abstract}
A method of the synthesis of digital filters based on transformation of complex response function of the analog filter prototype by replacement of a complex variable $p$ by a complex variable $z$ is considered. This method allows to synthesize digital IIR-filters with given requirements to frequency response that increases communication systems performance.

Key words: bilinear transformation method, synthesis of filters with infinite impulse response, the preemphasis of the frequency scale, extended bilinear transformation, precision filters.
\end{abstract}

\section{INTRODUCTION}

Digital filtering is being widely used for development of various data transmission systems and devices. Often very strict requirements concerning the accuracy of implementation of the required amplitude-frequency characteristic are given to digital filters. Well-known bilinear transform is being used for digital IIR-filters synthesis [1;2].

However, for bilinear transform frequency response of the digital filter is not the same as one of analog prototype filter. Traditionally, to achieve acceptable match between filterprototype response and one of digital filter, the pre-distortion method is used $[2 ; 6]$. Unfortunately, pre-distortions might not achieve required match between frequency response of the filter-prototype and digital filter.

Here we propose an approach to digital filters synthesis that let to avoid pre-distortions. It lets to implement precision filters with required frequency response. This approach is based on the generalization of known bilinear transform.

\section{DIGITAL FILTERS SYNTHESIS, BASED ON TRADITIONAL BILINEAR TRANSFORM}

$Z$-transform is widely used for study of discrete signals and linear discrete systems, instead of discrete Laplacian transform. It can be obtained via variables change in the discrete Laplacian transform [1;2]:

$$
z=e^{p T}
$$

where $T$ is sampling time period.
A method of transform of transfer function of analog prototype filter $H_{a}(p)$ into the system function of the digital filter $H(z)$, based on mapping of the complex variable $p$ into complex variable $z$, is widely used for digital filters synthesis. Main idea of this method is in the following $[1 ; 4]$.

Based on (1), we can obtain the following relation between $p$ and $z$ :

$$
p=\frac{1}{T} \ln (z)
$$

It should be note, that at immediate substitution of (2) into (1), it is possible to get required transfer function of the digital filter. However, this function, unfortunately, will be transcendent function. Moreover, transfer function of implementable digital filter this function can be represented in the form of the ratio of two polynomials [5]. To meet this requirement, the equation (2) must be changed by its fractionalrational approximation (in the form of the ratio of two polynomials).

Let use known expansion of the $\ln (z)$ function [Ошибка! Источник ссылки не найден.]:

$$
\ln (z)=2 \cdot \sum_{k=1}^{\infty} \frac{1}{2 k-1} \cdot\left(\frac{z-1}{z+1}\right)^{2 k-1}
$$

Usually, only the first term is used in the expansion (3), and higher order terms are not be used. As a result, we get the following approximation, taking into account (2):

$$
p=\frac{2}{T} \cdot \frac{z-1}{z+1}
$$

Based on (4), it is not difficult to get known bilinear $z$ transform [1Ошибка! Источник ссылки не найден.; 4-6]:

$$
p=\frac{2}{T} \cdot \frac{1-z^{-1}}{1+z^{-1}}
$$

The system function $H(z)$ of the digital filter can be obtained via the transfer function $H_{a}(p)$ of the analog prototype filter, based on (5) substitution: 


$$
H_{a}(p) \stackrel{p=\frac{2}{T} \cdot \frac{1-z^{-1}}{1+z^{-1}}}{\rightarrow} H(z)
$$

Transform (5) is fractional-rational first order function from $z^{-1}$. This transform provides unambiguous mapping of $p$ plane into $z$-plane. Digital filter is stable, if its analog prototype is stable. Optimality features of the analog prototype are kept in $z$-domain, because of unambiguous mapping of frequency axe $j \Omega$ into unit circle $e^{j \omega T}$.

Relationship between analog $\Omega$ and digital $\omega$ frequencies is actually non-linear, i.e., frequency scale is being deformed. Let find this relation, based on (5). An operator of $p=\sigma+j \Omega$ for frequency axe has the form of $p=j \Omega$, since $\sigma=0$ and $z=e^{j \omega T}$. Therefore, only frequency axe $j \Omega$ is considered in $p$-plane, and unit circle $e^{j \omega T}$ is considered in $z$-plane [4]:

$$
j \Omega=p=\frac{2}{T} \cdot\left(\frac{e^{j \omega T}-1}{e^{j \omega T}+1}\right)=j \cdot \frac{2}{T} \cdot \operatorname{tg} \frac{\omega T}{2},
$$

откуда следует, что

$$
\Omega=\frac{2}{T} \cdot \operatorname{tg} \frac{\omega T}{2}
$$

Connection between the scale of normalized frequencies of analog prototype filter $\Omega$ and the scale of normalized frequencies of the digital filter $\omega$ at ordinary bilinear $z$ transform is nonlinear (taking into account (7)). It is not possible to neglect this non-linearity, so we need to recalculate frequencies in digital domain into analog domain, and from analog domain into digital domain, to compensate frequency distortions.

Let consider proposed generalization of the traditional bilinear $z$-transform (5).

\section{GENERALIZATION OF KNOWN BILINEAR TRANSFORM AND ITS APPLICATION TO DIGITAL FILTERS SYNTHESIS}

To reduce non-linearity of the relationship between the scale of frequencies of digital filter $\omega$ and the scale of frequency of analog prototype filter $\Omega$, we propose not to limit by only the first term of (3) series, but to take into account several terms for an approximation of $p$ by complex variable $z$.

We have the following expression:

$$
j \Omega=p=\frac{1}{T} \cdot \ln (z) \approx \frac{2}{T} \cdot \sum_{k=1}^{N} \frac{1}{2 k-1} \cdot\left(\frac{z-1}{z+1}\right)^{2 k-1}
$$

Let introduce the following notation $[7 ; 8]$ :

$$
f_{N}(z)=\frac{2}{T} \cdot \sum_{k=1}^{N} \frac{1}{2 k-1} \cdot\left(\frac{z-1}{z+1}\right)^{2 k-1}
$$

Use the substitution:

$z=e^{j \omega T}$.

Then, we obtain:

$$
\frac{z-1}{z+1}=j \cdot \operatorname{tg} \frac{\omega T}{2}
$$

Where we have, taking into account (8):

$$
\Omega=\frac{2}{T} \cdot \sum_{k=1}^{N} \frac{1}{2 k-1} \cdot(-1)^{k-1} \cdot\left(\operatorname{tg} \frac{\omega T}{2}\right)^{2 k-1}
$$

Expression is the relationship between analog $\Omega$ and digital $\omega$ frequencies for the case of generalized bilinear transform (8).

Based on (9), we get the system function of the digital filter:

$$
H_{a}(p) \stackrel{p=f_{N}(z)}{\rightarrow} H(z)
$$

The order of the system function $H(z)$ and the order of the digital filter are equal to $n \cdot(2 \cdot N-1)$, where $n$ - is the order of an analog prototype filter; $N$ is the number of terms in (3). For traditional bilinear $z$-transform (5) we have $N=1$.

For example, for $N=3$ (3-d order approximation) we have:

$$
\begin{aligned}
& j \Omega=p=\frac{1}{T} \cdot \ln (z) \approx \frac{2}{T} \cdot \sum_{k=1}^{3} \frac{1}{2 k-1} \cdot\left(\frac{z-1}{z+1}\right)^{2 k-1}= \\
& =\frac{2}{T} \cdot\left(\left(\frac{z-1}{z+1}\right)+\frac{1}{3} \cdot\left(\frac{z-1}{z+1}\right)^{3}+\frac{1}{5} \cdot\left(\frac{z-1}{z+1}\right)^{5}\right)
\end{aligned}
$$

After substitution $z=e^{j \omega T}$ into (13) we get, using (10):

$$
j \Omega=p=\frac{2}{T} \cdot\left(j \cdot \operatorname{tg} \frac{\omega T}{2}+\frac{1}{3} \cdot\left(j \cdot \operatorname{tg} \frac{\omega T}{2}\right)^{3}+\frac{1}{5} \cdot\left(j \cdot \operatorname{tg} \frac{\omega T}{2}\right)^{5}\right),
$$

Where for $N=3$, we obtain the relation between scales of frequencies of analog prototype filter $\Omega$ and digital filter $\omega$ :

$$
\Omega=\frac{2}{T} \cdot\left(\operatorname{tg} \frac{\omega T}{2}-\frac{1}{3} \cdot\left(\operatorname{tg} \frac{\omega T}{2}\right)^{3}+\frac{1}{5} \cdot\left(\operatorname{tg} \frac{\omega T}{2}\right)^{5}\right)
$$

For $N=2$ (2-nd order approximation) we have:

$$
\Omega=\frac{2}{T} \cdot\left(\operatorname{tg} \frac{\omega T}{2}-\frac{1}{3} \cdot\left(\operatorname{tg} \frac{\omega T}{2}\right)^{3}\right)
$$

For large $N$ relationship between scales of frequencies of both analog and digital filters converges to linear dependency in the range of normalized frequencies in filter band pass [8].

\section{EXAMPLES OF THE DIGITAL FILTERS SYNTHESIS}

To study of proposed method, we have provided the synthesis of two low-pass Butterworth digital filters, those are met the requirements from [Ошибка! Источник ссылки не найден.]:

- $\quad$ boundary frequency of pass band is $F_{\text {pass }}=1 \mathrm{~Hz}$; 
- boundary frequency of non-pass band is $F_{\text {stop }}=2,414 \mathrm{~Hz}$;

- $\quad$ sampling frequency is $F_{s}=7 \mathrm{~Hz}$; sampling time period is $T=\frac{1}{F_{s}}$;

- non-uniformity of attenuation in pass band $\triangle A=0,5 \mathrm{~dB}$

- $\quad$ minimal accepted attenuation $A_{\min }=20 \mathrm{~dB}$.

Initially, let calculate the system function of the digital filter $H_{1}(z)$, using ordinary bilinear z-transform (5), that matches to the case of $N=1$, than let calculate the system function $H_{3}(z)$, using proposed transform in the case of $N=3$. In both cases an analog prototype filter is the same. Calculation is the following.

1. Bound frequencies $\Omega_{i}$ of the analog prototype filter (without predistortions) have the following values, those are the same with normalized vs. bound frequency $\Omega_{\text {pass }}$ frequencies:

$$
\Omega_{p}=\frac{\Omega_{\text {pass }}}{\Omega_{\text {pass }}}=1 ; \quad \Omega_{s}=\frac{\Omega_{\text {stop }}}{\Omega_{\text {pass }}}=3,4 .
$$

2. Calculation of the order of analog prototype filter $[2 ; 6]$ :

$$
n=\frac{\lg \left(\frac{10^{0,1 \cdot A_{\min }}-1}{10^{0,1 \cdot \Delta A}-1}\right)}{2 \cdot \lg \left(\Omega_{s}\right)}=2,453 .
$$

Since filter order must be integer, we get $n=3$.

3. Poles $p(k)$ of analog prototype filter are to be calculated, $k=1, \ldots n ; n$ is the number of poles of analog prototype filter, that is the same as its order [2Ошибка! Источник ссылки не найден.; 10;11]:

$$
p(k)=\frac{1}{\sqrt[n]{10^{0,1 \cdot \Delta A}-1}} \cdot\left(-\sin \left(\frac{\pi \cdot(2 k-1)}{2 n}\right)+j \cdot \cos \left(\frac{\pi \cdot(2 k-1)}{2 n}\right)\right)_{(17)}
$$

Based on (17), we calculate the following values of poles of analog prototype filter:

$$
\begin{gathered}
p(1)=-0,71+j \cdot 1,23 ; p(2)=-1,42 ; \\
p(3)=-0,71-j \cdot 1,23 .
\end{gathered}
$$

4. Transfer function of analog prototype filter is the following:

$$
\begin{gathered}
H_{a}(p)=\frac{1}{\sqrt{10^{0,1 \cdot \Delta A}-1} \cdot(p-p(1)) \cdot(p-p(2)) \cdot(p-p(3))}= \\
=2,863 \cdot \frac{1}{(p+1,42)} \cdot \frac{1}{\left(p^{2}+1,419 \cdot p+2,016\right)}
\end{gathered}
$$

Frequency response of analog prototype filter is given below:

$$
H_{a}(f)=2,863 \cdot \frac{1}{j \frac{f}{f_{\text {pass }}}+1,42} \cdot \frac{1}{\left(j \frac{f}{f_{\text {pass }}}\right)^{2}+1,419 \cdot j \frac{f}{f_{\text {pass }}}+2,016}
$$

5. For the case of ordinary bilinear $z$-transform, the substitution of (5) into (18) is being done, and after some simple transformations we get the following expression for the system function $H_{1}(z)$ of digital filter:

$$
\begin{gathered}
H_{a}(p) \stackrel{p=f_{1}(z)}{\rightarrow} H_{1}(z), \\
H_{1}(z)=0,095 \cdot\left(\frac{z+1}{z-0,17}\right) \cdot\left(\frac{z^{2}+2 z+1}{z^{2}-0,448 z+0,359}\right) .
\end{gathered}
$$

Frequency response of digital filter, using bilinear ztransform, is given below:

$$
\begin{aligned}
& H_{1}(f)=0,095 \cdot\left(\frac{e^{j \cdot 2 \pi \cdot f \cdot T}+1}{e^{j \cdot 2 \pi \cdot f \cdot T}-0,17}\right) \cdot \\
& \cdot\left(\frac{e^{j \cdot 2 \pi \cdot f \cdot T \cdot 2}+2 \cdot e^{j \cdot 2 \pi \cdot f \cdot T}+1}{e^{j \cdot 2 \pi \cdot f \cdot T \cdot 2}-0,448 \cdot e^{j \cdot 2 \pi \cdot f \cdot T}+0,359}\right)
\end{aligned}
$$

Expression (21) is given by the substitution of (1) into (20), taking into account normalization via sampling frequency.

The synthesis of the digital filter, based on generalized bilinear $z$-transform ( $N=3$ ) is similar. Using items $1 \ldots 4$, we obtain the same transfer function of analog prototype filter(18). But the next stage is different.

Let use the following transform

$$
p=f_{3}(z)=\frac{2}{T} \cdot\left(\left(\frac{z-1}{z+1}\right)+\frac{1}{3} \cdot\left(\frac{z-1}{z+1}\right)^{3}+\frac{1}{5} \cdot\left(\frac{z-1}{z+1}\right)^{5}\right)
$$

After substitution (22) into (18) we obtain:

$$
H_{a}(p) \stackrel{p=f_{3}(z)}{\rightarrow} H_{3}(z)
$$

We get system function $H_{3}(z)$ of digital filter (3-d order generalization):

$$
H_{3}(z)=0,033 \cdot \frac{z^{5}+5 z^{4}+10 z^{3}+10 z^{2}+5 z+1}{z^{5}+2,25 z^{4}+4,5 z^{3}+1,5 z^{2}+0,72 z-0,4} .
$$




$$
\cdot \frac{\left(\begin{array}{l}
z^{10}+10 z^{9}+45 z^{8}+120 z^{7}+210 z^{6}+ \\
+252 z^{5}+210 z^{4}+120 z^{3}+45 z^{2}+10 z+1
\end{array}\right)}{\left(\begin{array}{l}
z^{10}+4 z^{9}+13 z^{8}+21 z^{7}+28,9 z^{6}+ \\
+19,5 z^{5}+15,3 z^{4}+5,8 z^{3}+3,8 z^{2}+0,8 z+0,4
\end{array}\right)}
$$

6. Polynomials of 2-nd degree with real coefficients are being generated, based on conjugated zeros and conjugated poles. These polynomials are further used for both nominators and denominators of chains.

Frequency response of the digital filter, based on generalized $z$-transform, can be obtained by the exchange of $z \rightarrow e^{j \cdot 2 \pi \cdot f \cdot T}$ in (23).

Let compare frequency response of received digital filters between each other and with frequency response of analog prototype filter with 3 -d order.

Frequency responses of attenuation are shown by the Fig.1 for analog prototype filter and synthesized digital filters:

- $|A 1(f)|$ is for digital filter, based on an ordinary bilinear z-transform;

- $|A 3(f)|$ is for digital filter, based on generalized bilinear z-transform;

- $|A a(f)|$ is for analog prototype filter of 3-d order.

Filter cutoff frequency of the filter, using an ordinary bilinear $z$-transform, is equal to $F_{c u t}=1,37$. Filter cutoff frequency of analog prototype filter, and obtained digital filter (using 3-d order bilinear z-transform) are same and it is equal to $F_{\text {cut }}=1,42$.

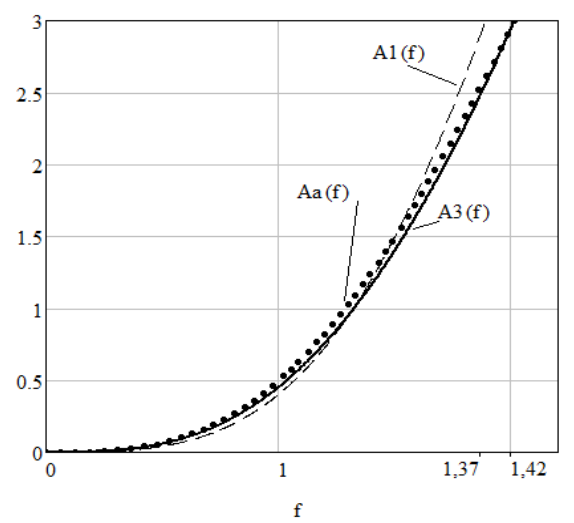

Fig. 1. Curves of deviation of filters in the passband

From Fig. 1 one can see that frequency response of the digital filter, based on generalized bilinear $z$-transform, is quite close to one of analog prototype filter in working frequency domain. It lets to avoid pre-distortions and to improve accuracy of frequency response of digital filter.

\section{CONCLUSION}

Based on described results, one can see that implementation of proposed generalized bilinear $z$-transform lets to get digital filter with frequency response very close to ones of analog prototype filter. It lets avoid predistortions those are required for traditional bilinear $z$-transform.

Increase of the order of digital filter (and its complexity increase) is the disadvantage of proposed method. Practically, a tradeoff should be found between frequency response accuracy and filter complexity.

\section{REFERENCES}

1. Оппенгейм А., Шафер Р. Цифровая обработка сигналов. 2-е изд. М.: Tехносфера, 2007, [Oppengame A., Shafer R. Digital signal processing. 2nd ed. Moscow: Technosphera, 2007].

2. Соболев В.Н. Теория электрических цепей. М.: Горячая линия Телеком, 2014. [Sobolev V.N. Theory of electric circuits. Moscow: Goryachaya Linia - Telecom, 2014].

3. Фихтенгольц Г. М. Курс дифференциального и интегрального исчисления. 8-е изд. М.: Физматлит, 2003. Т 1. [Fihtengolts G.M. Course of differential and integral calculus. 8th ed. Moscow: Fizmatlit, 2003. Vol. I].

4. Баскаков С.И. Радиотехнические цепи и сигналы. М.: Высшая школа, 2000. [Baskakov S.I. Radiotechnical circuits and signals. Moscow: Visshaya shkola, 2000].

5. Рабинер Л., Гоулд Б. Теория и применение цифровой обработки сигналов. М.: Мир, 1978. [Rabiner L. R., Gold V. Theory and application of digital signal processing. Moscow: Mir, 1978].

6. Смит С. Научно-техническое руководство по цифровой обработке сигналов. М.: Додэка, 2008. [Smit S. Digital signal processing. Practical manual for engineers and scientists. Moscow: Dodeka XXI, 2008].

7. КрейнделинВ.Б., Григорьева Е.Д. Развитие метода билинейного преобразования для синтеза цифро- вых фильтров // Международная научно-техническая конференция "INTERMATIC-2017". Ноябрь 2017. M., 2017. C. 1183-1185. [Kreyndelin V.B., Grigorieva E.D. Development of the method of bilinear transform for digital filters synthesis. Materials of International Conference «INTERMATIC-2017». Fundamental problems of radioelectronic devices development. November, 2017. Moscow, 2017. Р. 1183-1185.

8. Крейнделин В.Б., Григорьева Е.Д. Методика повышения показателей качества цифровых фильтров в системах связи // Труды Международной научно-технической конференции «Телекоммуникационные и вычислительные системы - 2017». М., 2017. C. 162-166. [Kreyndelin V.B., Grigorieva E.D. Method of quality increase of digital filters in communication systems // Materials of International Conference "Telecommunication and computational systems - 2017'. Moscow, 2017. P. 162-166].

9. Kwaha B.J., Kolawole E.A., Batu A.M. The design and implementation of a digital infinite impulse response (IIR) lowpass Butterworth filter - A comparison of Matlab and Bilinear transformation methods // Indian Journal of Science and Technology. 2011. Vol. 4, N 4 P. 451-455.

10. Марченко А.П. Частотные фильтры: пассивные, активные и цифровые. М.: Горячая линия - Телеком, 2017. [Marchenko A.P. Digital filters: passive, active and digital. Moscow: Goryachaya Linia Telecom, 2017].

11. Смирнов Н.И., Фриск В.В, Теория электрических цепей. М.: Горячая линия - Телеком, 2018. [Smirnov N.I., Frisk V.V. Theory of electric circuits: conspect of Lectures. Moscow: Goryachaya Linia - Telecom, 2018]. 